\title{
AMINOÁCIDOS LIVRES MAJORITÁRIOS NO SUCO DE CAJU: VARIAÇÃO AO LONGO DA SAFRA ${ }^{1}$
}

\author{
MARIA ELISABETH BARROS DE OLIVEIRA², GERARDO SÉRGIO FRANCELINO DE OLIVEIRA², \\ GERALDO ARRAES MAIA 3 , RENATO DE AZEVEDO MOREIRA ${ }^{4}$, \\ ANA CRISTINA DE OLIVEIRA MONTEIRO ${ }^{4}$
}

\begin{abstract}
RESUMO - Visando a contribuir para o conhecimento dos aminoácidos livres majoritários presentes no suco de caju (Anacardium occidentale L.), estudou-se o seu comportamento ao longo da safra de 1995, no período de agosto a novembro, no clone de cajueiroanão precoce, CCP 09, com aptidão para a produção de suco. O suco foi obtido de cajus cultivados no município de Pio IX, Estado do Piauí, Brasil. Os frutos foram colhidos em intervalos de 21 dias, perfazendo cinco amostragens. Os aminoácidos foram determinados utilizando-se um auto-analisador de aminoácidos. Preliminarmente, foram feitos ensaios para conhecer o espectro total dos aminoácidos livres presentes no suco; destes, foram escolhidos os oito majoritários, sobre os quais está baseado o estudo. Os aminoácidos majoritários encontrados, na ordem decrescente, foram: alanina, serina, fenilalnina, leucina, ácido glutâmico, ácido aspártico, prolina e tirosina
\end{abstract}

Termos para indexação: Aminoácidos livres, suco de caju, clone, cashew apple.

\section{MAJOR FREE AMINO ACIDS IN CASHEW APPLE JUICE: BEHAVIOUR DURING THE HARVEST SEASON}

\begin{abstract}
The major free amino acids in cashew apple juice were studied during the crop season August to November 1995. The cashew apples were obtained from the clone CCP 09 cultivated in the county of Pio IX, state of Piauí-Brazil. Analysis were carried out in five samples harvested at twenty-one days intervals by using an amino acid analyser. The amino acids present in the juice were preliminary evaluated. Only the major eight ones were selected. The major amino acids detected, in decreasing order were: alanine, serine, phenylalanine, leucine, glutamic acid, aspartic acid, proline and tyrosine.
\end{abstract}

Index terms: free amino acid, juice, cashew apple.

\section{INTRODUÇÃO}

Os aminoácidos são unidades químicas de baixo peso molecular (75-204) que possuem, pelo menos, um grupamento amina e outro carboxila ligados ao mesmo átomo de carbono. Os tecidos tanto animais quanto vegetais possuem uma pequena porção (1-3\%) do nitrogênio aminoacídico na forma livre, enquanto o restante está na forma protéica (Farfan, 1994a). Apesar de não apresentarem valor nutricional, os aminoácidos livres são considerados de extrema importância com relação à qualidade sensorial e tecnológica dos produtos, assim como do ponto de vista da autenticidade da matéria-prima ou do produto final (Farfan, 1994b).

Os aminoácidos livres nos frutos, sendo essencialmente solúveis em água, existem como tal em sucos. Em geral, não têm sido feitos muitos trabalhos sobre aminoácidos em frutos, provavelmente, porque os frutos são um produto de baixo teor de nitrogênio e de pequeno significado nutricional como alimento protéico. Considerável interesse surge, no entanto, quando o conteúdo de aminoácidos influencia o processamento de frutos, por exemplo, nas indústrias de fermentação de vinhos e cidras, e nas reações de escurecimento de produtos cítricos e frutas desidratadas (Burroughs, 1970).

Atualmente, vem surgindo um maior interesse na busca do conhecimento sobre o conteúdo de aminoácidos livres em sucos, visando a obter um perfil característico do espectro destes compostos, em diferentes tipos de sucos, já que existem estudos que comprovam ser esse perfil específico para cada tipo de fruta (Wallrauch e Faethe, 1988).

Price et al. (1975) estudaram os aminoácidos livres de sucos de cajus, obtidos dos tipos "vermelho" e "amarelo", classificados como doce, azedo e adstringente, e encontraram que os aminoácidos predominantes eram: alanina, ácido aspártico, ácido glutâmico, serina, treonina e prolina. O triptofano foi encontrado somente em mínimas quantidades e constataram sua ausência em amostras de sucos ácidos. Outros aminoácidos presentes somente em pequenas quantidades foram metionina, cistina e histidina.

Ara (1988) determinou os teores de aminoácidos livres do suco de caju reconstituído $\left(11,5^{\circ} \mathrm{Brix}\right)$, a partir do suco clarificado concentrado e suco de acerola a $7^{\circ}$ Brix. No suco de caju, destacam-se o ácido aminobutírico, alanina e prolina, serina 
e ácido aspártico, e, no suco de acerola, predominam a asparagina, prolina e alanina. Em ambos, a metionina está presente em mínimas quantidades.

Haendler \& Duverneuil (1970) encontraram que valina, ácido aspártico, treonina, lisina e alanina estão presentes em quantidades apreciáveis no caju, e somente traços de prolina e serina, enquanto constataram a ausência de metionina.

Independentemente do tipo de fruta, oito aminoácidos são responsáveis pela peculiaridade do espectro de aminoácidos. Juntamente com amônia, prolina, ácido aspártico, serina, asparagina, ácido glutâmico, alanina, ácido g - aminobutírico e arginina representam em torno de 90 a $95 \%$ dos aminoácidos livres na maioria dos sucos de frutas ou polpas de frutas (Wallrauch \& Faethe, 1988).

A literatura relata que a composição dos aminoácidos livres é influenciada pela cultivar, condições climáticas (Elahi \& Khan, 1971; Wallrauch, 1988), fatores culturais (Elahi \& Khan, 1971; Vandercook \& Price, 1972; Wallrauch \& Faethe, 1988), época de colheita (Bernardi et al., 1991; Di Giacomo et al., 1979) e maturação do fruto (Wallrauch, 1980).

Embora exista na literatura uma quantidade razoável de trabalhos sobre aminoácidos livres em suco de frutas, a maioria refere-se a frutos de clima temperado ou subtropical; destes, destacam-se os cítricos, cujo espectro, bastante estudado, revela a prolina como aminoácido-chave .

Visando a contribuir para o conhecimento dos aminoácidos livres majoritários do suco de caju, estudou-se a sua variação ao longo da safra de 1995 , no período de agosto a novembro, objetivando detectar possíveis alterações desses compostos em decorrência da estação, no clone de cajueiroanão precoce, CCP 09, com aptidão para a produção de suco.

\section{MATERIALEMÉTODOS}

Os frutos utilizados neste trabalho constaram de pedúnculos de caju de cajueiro-anão precoce (Anacardium occidentale, L.) do clone CCP 09, plantado em 1993, proveniente do Município de Pio IX, Estado do Piauí, Brasil.

Para efeito de tomada de decisão com relação à primeira colheita, considerou-se o período inicial, como sendo aquele no qual os cajueiros apresentavam razoável número de frutos maduros, sendo então denominados neste experimento, como início da safra. A partir de então, a cada 21 dias, os cajus eram colhidos e enviados ao laboratório para análise, obtendo-se, então, cinco amostragens ao longo da safra.

Os pedúnculos foram colhidos pela manhã, descastanhados, embalados em sacos plásticos acondicionados em caixas de isopor com gelo, e enviados no mesmo dia ao laboratório, onde foram lavados, descartados os frutos amassados, e, em seguida, foram embalados em sacos plásticos e armazenados em congelador à temperatura de $-18^{\circ} \mathrm{C}$, para as análises posteriores.

Obteve-se o suco integral de caju, através de prensagem manual, seguindo-se de clarificação através de centrifugação a $7.000 \mathrm{rpm}$ durante quinze minutos. Ao volume de $10 \mathrm{~mL}$ do sobrenadante, adicionaram-se $2,5 \mathrm{~mL}$ da solução de ácido sulfossalicílico a $15 \%$, com a finalidade de desproteinizar a amostra. Agitou-se, deixou-se em repouso por dez minutos, em seguida, levou-se novamente à centrífuga, nas mesmas condições anteriores, transferindo o sobrenadante, que contém os minoácidos livres, para tubos de vidro com tampa rosqueável, armazenando-se em congelador a $-18^{\circ} \mathrm{C}$, para posterior análise. O suco desproteinizado foi filtrado em membrana "milipore" de $45 \mu \mathrm{m}$, e, a seguir, diluído na proporção 1:1 com tampão citrato

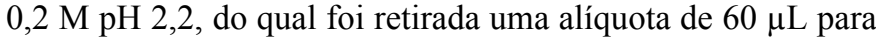
aplicação diretamente no aparelho analisador.

A análise quantitativa dos aminoácidos foi realizada no auto-analisador de aminoácidos, da marca Pharmacia, de acordo com o método de Spackman et al. (1958), modificado para uso do sistema Biochrom 20 Pharmacia.

O teor de aminoácidos das amostras foi determinado por comparação com uma solução-padrão injetada no aparelho contendo $10 \mathrm{hmoles} / \mathrm{mL}$ de aminoácidos, e levando em conta a concentração total de aminoácidos (com base na concentração de $\mathrm{N}_{2}$ na amostra).

O Triptofano foi determinado pelo método espectrofotométrico de Goodwin \& Morton (1946), modificado por Beaven \& Holiday (1952). Utilizou-se um espectrofotômetro UV-VIS, marca Pharmacia modelo LKB-Ultrospec III. Retirou-se $750 \mathrm{~mL}$ da solução da amostra e diluiu-se em igual quantidade de solução de $\mathrm{NaOH}$ 0,2 N e levou-se para leitura a 280 e $294 \mathrm{~nm}$. A relação tirosina/triptofano foi determinada pela fórmula:

$$
\frac{M_{\text {tir }}}{M_{\text {trip }}}=\frac{0,592 \times E_{294}-0,263 \times E_{280}}{0,263 \times E_{280}-0,170 \times E_{294}}
$$

Os reagentes para análise automática dos aminoácidos livres, foram obtidos da Pharmacia, Uppsala, Suécia. Os demais reagentes utilizados foram de grau analítico.

Para a obtenção dos dados referentes a aminoácidos livres presentes no suco de caju, consideram-se 5 períodos de colheita distanciados de 21 dias cada um, os quais se constituíram nos tratamentos. O delineamento empregado foi inteiramente casualizado, com 3 repetições. Os dados paramétricos obtidos foram analisados estatisticamente, segundo a sua variância, através do teste $\mathrm{F}$, e as médias comparadas através do teste de Tukey.

\section{RESULTADOS E DISCUSSÃO}

Os resultados referentes à evolução dos aminoácidos livres, com os respectivos cálculos estatísticos detectados no suco de caju do clone CCP 09, encontram-se nas Tabelas 1 e 2. $\mathrm{O}$ teor de alanina livre do suco de caju, clone CCP 09 , variou ao longo da safra, de $246,93 \mu \mathrm{Mol} / 100 \mathrm{~mL}$ a $434,23 \mu \mathrm{Mol} / 100 \mathrm{~mL}$, apresentando valor médio de $336,48 \mu \mathrm{Mol} / 100 \mathrm{~mL}$, o qual é compatível com os valores médios encontrados por Price et al. (1975) em suco de caju classificado como doce $(312 \mu \mathrm{Mol} / 100$ $\mathrm{mL})$ e em suco ácido $(362 \mu \mathrm{Mol} / 100 \mathrm{~mL})$. O valor detectado diverge do valor médio encontrado por Ara (1988), em suco de caju reconstituído $(249 \mu \mathrm{Mol} / 100 \mathrm{~mL})$. O comportamento da alanina, ao longo da safra, foi bastante variável, exibindo um pico no meio da safra e, a seguir, uma tendência de decréscimo no final (Figura 1). As diferenças detectadas entre as médias dos períodos de tempo foram significativas ao nível $(\mathrm{p}<0,0004)$ de 
probabilidade, pelo teste de Tukey.

A serina livre variou de 177,87 a $359,07 \mu \mathrm{Mol} / 100 \mathrm{~mL}$ com média de 273,01 $\mu \mathrm{Mol} / 100 \mathrm{~mL}$. Esse aminoácido, apresentou um comportamento ao longo da safra, que evidencia, pelas oscilações, uma tendência geral de crescimento, sugerindo que, possivelmente, ocorre síntese ou acúmulo de serina (Figura 1). Estes valores detectados contradizem Haendler \& Duverneuil (1970), que relatam ter encontrado apenas traços desse aminoácido presente no suco de caju. Outros autores que estudaram o mesmo tipo de suco, encontraram valores médios deste aminoácido, bastante diferentes, $114 \mu \mathrm{Mol} / 100 \mathrm{~mL}$ para o suco reconstituído (Ara, 1988), $131 \mu \mathrm{Mol} / 100 \mathrm{~mL}$ em suco doce, $83 \mu \mathrm{Mol} / 100 \mathrm{~mL}$ para o suco ácido e $110 \mu \mathrm{Mol} / 100 \mathrm{~mL}$ em suco adstringente (Price et al., 1975). As diferenças detectadas entre as médias dos períodos de tempo foram significativas ao nível $(\mathrm{p}<0,0070)$ de probabilidade, pelo teste de Tukey.

A fenilalanina livre variou de 146,1 a $222,0 \mu \mathrm{Mol} / 100 \mathrm{~mL}$ com média de $175,6 \mu \mathrm{Mol} / 100 \mathrm{~mL}$. Esse aminoácido mostrou um comportamento com poucas oscilações, exibindo um discreto aumento no meio da safra e, a seguir, uma tendência de decréscimo ao final (Figura 1). O valor médio detectado para o suco de caju, ao longo da safra, encontra-se bem acima dos valores médios detectados pelos demais autores que estudaram o suco de caju. Ara (1988) encontrou, para o suco de caju reconstituído, valor médio de $26 \mu \mathrm{Mol} / 100 \mathrm{~mL}$ para a fenilalanina livre, enquanto Price et al. (1975) encontraram para o suco doce, $25 \mu \mathrm{Mol} / 100 \mathrm{~mL}$, para o suco ácido, $32 \mu \mathrm{Mol} / 100 \mathrm{~mL}$, e para o suco adstringente, $53 \mu \mathrm{Mol} / 100 \mathrm{~mL}$. Bielig et al. (1982) referem em termos de pequenas quantidades deste aminoácido, em sucos como de laranja (18 $\mu \mathrm{Mol} / 100 \mathrm{~mL}),(40 \mu \mathrm{Mol} / 100 \mathrm{~m})$. As diferenças detectadas entre as médias dos períodos de tempo foram significativas ao nível $(\mathrm{p}<0,0001)$ de probabilidade, pelo teste de Tukey.

O teor de leucina livre apresentou valor mínimo de 139,6 $\mu \mathrm{Mol} / 100 \mathrm{~mL}$ e máximo de $236,2 \mu \mathrm{Mol} / 100 \mathrm{~mL}$, com média de $178,1 \mu \mathrm{Mol} / 100 \mathrm{~mL}$, ao longo da safra. Este aminoácido apresentou um comportamento variável com tendência geral de decréscimo com o desenrolar da safra (Figura 1). Os resultados encontrados diferem dos valores observados pelos outros autores para o suco de caju doce $70 \mu \mathrm{Mol} / 100 \mathrm{~mL}$, ácido 95 $\mu \mathrm{Mol} / 100 \mathrm{~mL}$ e adstringente $57 \mu \mathrm{Mol} / 100 \mathrm{~mL}$ (Price et al., 1975) e para o suco de caju reconstituído $71 \mu \mathrm{Mol} / 100 \mathrm{~mL}$ (Ara, 1988). Ventura e Lima (1959) citam 14 diferentes aminoácidos presentes no suco de caju, aparecendo em maior abundância alanina, valina e leucina, seguidos de serina, ácido glutâmico, prolina e triptofano. As diferenças detectadas entre as médias dos períodos de tempo foram significativas ao nível $(\mathrm{p}<0,0001)$ de probabilidade, pelo teste de Tukey.

O teor de ácido glutâmico livre no suco de caju variou, ao longo da safra, de 114,9 a174,9 $\mu \mathrm{Mol} / 100 \mathrm{~mL}$, com média de $148,4 \mu \mathrm{Mol} / 100 \mathrm{~mL}$. Este aminoácido mostrou um comportamento com pouca variação, com leve tendência de aumento com o avanço da estação (Figura 1). O valor médio detectado encontrase um pouco abaixo dos teores observados por Price et al. (1975) para o suco de caju doce $(185 \mu \mathrm{Mol} / 100 \mathrm{~mL})$ e para o suco adstringente $(190 \mu \mathrm{Mol} / 100 \mathrm{~mL})$, divergindo, no entanto, dos teores detectados pelos mesmos autores para o suco ácido (91 $\mu \mathrm{Mol} / 100 \mathrm{~mL})$, e para o suco de caju reconstituído $(72 \mu \mathrm{Mol} / 100$ $\mathrm{mL}),($ Ara, 1988). As diferenças detectadas entre as médias dos períodos de tempo foram significativas ao nível $(\mathrm{p}<0,0001)$ de probabilidade, pelo teste de Tukey.

O teor de ácido aspártico livre variou, ao longo da safra, de 69,8 a 132,0 $\mu \mathrm{Mol} / 100 \mathrm{~mL}$, com média de $87,6 \mu \mathrm{Mol} / 100 \mathrm{~mL}$. Este aminoácido mostrou um comportamento com pouca oscilação, apresentando um crescimento no meio da safra , caracterizado por um pico e, após, um decréscimo (Figura 1). O valor médio obtido encontra-se próximo aos valores mencionados por Ara (1988) para o suco de caju reconstituído $(110 \mu \mathrm{Mol} / 100$ $\mathrm{mL}$ ) e aos teores médios encontrados por Price et al. (1975) para o suco de caju ácido $(69 \mu \mathrm{Mol} / 100 \mathrm{~mL})$, porém discordantes dos teores detectados pelos mesmos autores para os sucos doce $(175 \mu \mathrm{Mol} / 100 \mathrm{~mL})$ e adstringente $(147 \mu \mathrm{Mol} / 100 \mathrm{~mL})$. As diferenças detectadas entre as médias dos períodos de tempo foram significativas ao nível $(\mathrm{p}<0,0001)$ de probabilidade, pelo teste de Tukey.

O teor de prolina livre variou, ao longo da safra, de $105,8 \mu \mathrm{Mol} / 100 \mathrm{~mL}$ a 203,9 $\mu \mathrm{Mol} / 100 \mathrm{~mL}$, com média de 158,7 $\mu \mathrm{Mol} / 100 \mathrm{~mL}$. Este aminoácido mostrou um comportamento bastante variável, apresentando, no entanto, uma tendência geral de decréscimo com o decorrer da safra (Figura 1). O valor médio detectado encontra-se próximo aos valores médios observados por Price et al. (1975), para o suco de caju classificado como doce $(109 \mu \mathrm{Mol} / 100 \mathrm{~mL})$, porém bem acima da média para os sucos de caju ácido e adstringente, respectivamente $(67 \mu \mathrm{Mol} / 100 \mathrm{~mL}) \mathrm{e}$ $(59 \mu \mathrm{Mol} / 100 \mathrm{~mL})$. Ara (1988) encontrou valores de prolina livre um pouco acima ao analisar o suco de caju reconstituído (211 $\mu \mathrm{Mol} / 100 \mathrm{~mL}$ ). A prolina é o principal aminoácido presente no suco de laranja madura, representando em torno de $50 \%$ do total de aminoácidos livres (Tadeo, 1988). A medida do nível de prolina livre é usada na Europa para detectar diluições excessivas do suco de laranja, como também, detectar a adição de suco de tangerina (Citrus reticulata sp.) ao suco de laranja, através do decréscimo no valor de prolina e aumento no nível de éster de criptoxantina (corante abundante na tangerina) (Kuneman et al 1988; Ooghe \& De Waele, 1982a; Ooghe \& De Waele, 1982b). As diferenças detectadas entre as médias dos períodos de tempo foram significativas ao nível $(\mathrm{p}<0,0001)$ de probabilidade, pelo teste de Tukey.

O teor de tirosina livre variou de 71,2 a 155,4 $\mu \mathrm{Mol} / 100$ $\mathrm{mL}$, com média de 155,5 $\mu \mathrm{Mol} / 100 \mathrm{~mL}$. Este aminoácido mostrou um comportamento muito homogêneo, caracterizado por uma leve tendência linear de aumento com o avanço da safra (Figura 1). Diversos autores que estudaram sua composição, em outros frutos, encontraram valores bem menores como para o suco de caju classificado como doce $(59 \mu \mathrm{Mol} / 100 \mathrm{~mL})$, ácido $(57 \mu \mathrm{Mol} /$ $100 \mathrm{~mL})$ e adstringente $(83 \mu \mathrm{Mol} / 100 \mathrm{~mL})$, (Price et al., 1975) e para o suco de caju reconstituído $(51 \mu \mathrm{Mol} / 100 \mathrm{~mL}),($ Ara, 1988). As diferenças detectadas entre as médias dos períodos de tempo foram significativas ao nível $(\mathrm{p}<0,0001)$ de probabilidade, pelo teste de Tukey.

Wallrauch (1980), referindo-se ao suco de laranja, reporta que as faixas de concentração dos aminoácidos individuais são influenciadas pela cultivar, clima, área de cultivo e maturidade dos frutos; sendo assim, são plenamente justificáveis as diferenças constatadas entre os dados obtidos e entre os diversos autores que estudaram o assunto, mesmo porque se trata de material genético selecionado.

As discrepâncias encontradas com relação aos teores de alguns aminoácidos livres, quando comparados com outros 
TABELA 1 - Valores médios dos aminoácidos livres majoritários ( $\mu \mathrm{Mol} / 100 \mathrm{~mL})$ presentes no suco de caju do clone CCP 09, ao longo da safra de $1995^{1}$.

\begin{tabular}{|c|c|c|c|c|c|}
\hline A m inoácidos livres & Inic ia l & $21 \mathrm{dias}$ & $42 \mathrm{~d}$ ia $\mathrm{s}$ & $63 \mathrm{~d}$ ia $\mathrm{s}$ & 84 dia s \\
\hline A lanina & $331,27 \mathrm{bc}$ & $304,50 \mathrm{c}$ & $434,23 a$ & $365,47 b$ & $246,93 \mathrm{~d}$ \\
\hline S erin a & $177,87 \mathrm{c}$ & $274,10 \mathrm{ab}$ & $253,00 \mathrm{bc}$ & $359,07 \mathrm{a}$ & $301,03 \mathrm{ab}$ \\
\hline F e nila la nina & $171,20 \mathrm{bc}$ & $157,17 \mathrm{~cd}$ & $222,0 \mathrm{a}$ & $181,73 \mathrm{~b}$ & $146,07 \mathrm{~d}$ \\
\hline Leuc in a & $236,23 \mathrm{a}$ & $148,33 \mathrm{c}$ & $214,70 \mathrm{~b}$ & $151,53 \mathrm{c}$ & $139,57 \mathrm{c}$ \\
\hline Ácido aspártico & $75,83 \mathrm{bc}$ & $75,97 \mathrm{bc}$ & $131,97 \mathrm{a}$ & $84,47 b$ & $69,77 \mathrm{c}$ \\
\hline P rolin $a$ & $203,87 \mathrm{a}$ & $192,43 \mathrm{a}$ & $105,77 \mathrm{~b}$ & $177,43 \mathrm{a}$ & $114,00 \mathrm{~b}$ \\
\hline Tirosin a & $71,23 \mathrm{e}$ & $92,27 \mathrm{~d}$ & $117,40 \mathrm{c}$ & $141,37 \mathrm{~b}$ & $155,40 \mathrm{a}$ \\
\hline
\end{tabular}

${ }^{1}$ Médias seguidas da mesma letra, na mesma linha, não diferem significativamente, ao nível de $5 \%$ de probabilidade, pelo teste de Tukey.

TABELA 2 - Variação estatística das médias $(\mu \mathrm{Mol} / 100 \mathrm{~mL})$ das determinações dos aminoácidos livres majoritários do suco de caju (Anacardium occidentale L.) do clone CCP 09, ao longo da safra de 1995.

\begin{tabular}{lcccccc}
\hline $\begin{array}{l}\text { A minoácidos } \\
\text { livres }\end{array}$ & $\begin{array}{c}\text { M édia } \\
(\mathrm{m})\end{array}$ & $\begin{array}{c}\text { Desvio- } \\
\text { padrão } \\
(\mathrm{s})\end{array}$ & $\begin{array}{c}\text { Coeficiente } \\
\text { de variação } \\
\text { C V }(\%)\end{array}$ & $\begin{array}{c}\text { Intervalo de } \\
\text { confiança } \\
\text { IC }(95 \%)\end{array}$ & \multicolumn{2}{c}{ M ánimo } \\
A lanina & 336,48 & $\pm 11,78$ & 3,5 & $329,23-343,73$ & 231,3 & 446,4 \\
Serina & 273,01 & $\pm 28,31$ & 10,37 & $255,80-290,22$ & 171,5 & 360,5 \\
Fenila lanina & 175,63 & $\pm 6,85$ & 3,9 & $171,61-179,65$ & 139,3 & 243,1 \\
Leucina & 178,05 & $\pm 6,59$ & 3,7 & $174,32-181,82$ & 130,6 & 243,5 \\
Ácido glutâmico & 148,43 & $\pm 4,30$ & 2,9 & $145,97-150,89$ & 109,8 & 176,2 \\
Ácido aspártico & 87,60 & $\pm 4,12$ & 4,7 & $85,21-89,99$ & 63,6 & 135,6 \\
Prolina & 158,70 & $\pm 16,19$ & 10,2 & $129,13-188,27$ & 66,0 & 209,9 \\
Tirosina & 115,53 & $\pm 4,39$ & 3,8 & $112,97-118,09$ & 68,5 & 160,4 \\
\hline
\end{tabular}

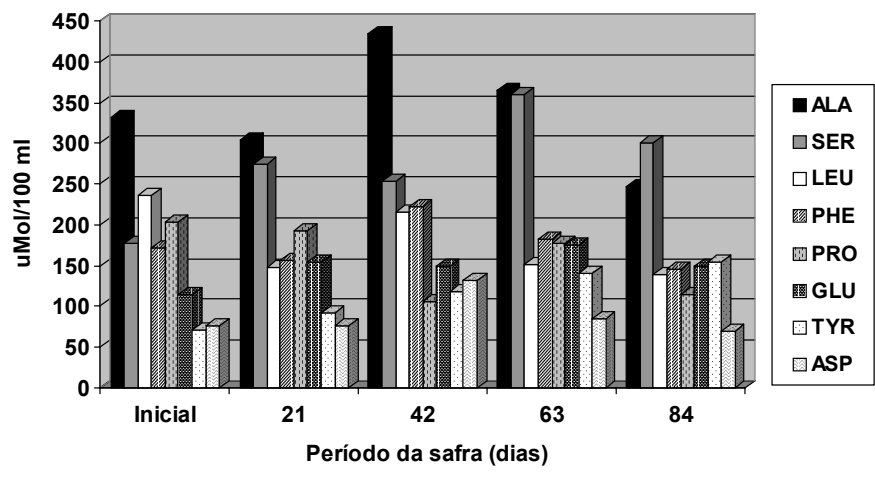

FIGURA 1 - Evolução dos aminoácidos livres majoritários presentes no suco de caju do clone CCP-09, ao longo da safra. sucos de caju, podem ser atribuídas às diferenças de variedade, influência da área de cultivo, tratos culturais ou fatores ambientais e por tratar-se de material selecionado.

As variações dos parâmetros estudados ao longo da safra poderiam ser explicadas, não só em função da disponibilidade de nutrientes do solo no período, como também do número de frutos por planta, condições climáticas e, sobretudo, por fatores genéticos.

Em função da importância do perfil dos aminoácidos livres para avaliar a autenticidade de sucos de frutas, e como ferramenta poderosa para detectar adulteração ou fraude em produtos industrializados comercializados, faz-se necessário estudos mais abrangentes destes aminoácidos no suco de caju autêntico fresco e processado, envolvendo um número maior de clones de diversas regiões de cultivo para, assim, obter um espectro mais representativo dos aminoácidos livres presentes. 


\section{AGRADECIMENTO}

Ao Conselho Nacional de Desenvolvimento Científico e Tecnológico (CNPq), pelo auxílio financeiro.

\section{CONCLUSÕES}

1. Os oito aminoácidos livres majoritários detectados no suco de caju do clone CCP 09, ao longo da safra de 1995, são, em ordem decrescente de concentração: alanina, serina, leucina, fenilalanina, prolina, ácido glutâmico, tirosina e ácido aspártico.

2. A alanina e a serina parecem ser os aminoácidos-chave para a identificação do suco de caju, uma vez que permaneceram majoritários ao longo do período da safra.

3. Todos os aminoácidos estudados apresentaram variações altamente significativas em suas concentrações no suco ao longo do período considerado.

\section{REFERÊNCIAS BIBLIOGRÁFICAS}

ARA, V. Cajuäpfel-und Acerolaprodukte, woher kommmen sie, wie schmecken sie. Fluessiges Obs, v.17, p.380-382, 1988.

BEAVEN, G.H.; HOLLIDAY, E.R. Ultraviolet spectra of protein and amino acids. In: NEURATH, H. (Ed). Advances in protein chemistry, San Diego, v. 7, p. 319, 1952.

BERNARDI, C. M.; FREYRE, M. R.; BAIGORRIA, C.; ZANNIER, M.; MINETTI, M.; ROZYCHI, V.; DRESCHER, R. W. Nota. Características químicas de cremogenados de naranjas argentinas. Su utilidad en la detección de adulteraciones. Revista de Agroquímica y Tecnologia de Alimentos, Valencia, v. 31, n. 4, p. 566-572, 1991.

BIELIG, H.J.; FAETHE, W.; KOCH, J.; WALLRAUCH, S.; WUCHERPFENNIG, K. Standard values and ranges of specific reference numbers for apple juice, grape juice and orange juice. Fluessiges Obst, Schoenborn, v.49, n.3a, p.188-199. 1982.

BURROUGHS, L. F. Amino Acids. In: HULME, A. C. (ed.). The Biochemistry of Fruits and their Products. New York: Academic Press Inc, 1970. v.1 p. 119 - 146.

DI GIACOMO, A.; BOVALO, F.; LEUZZI, V.; GALTIERI, A.; STAGNO-D'ALCONTRES, I. The free amino acids in sweet orange juice produced industrially from cv. Biondo Comune of Piana di Rosarmo (1978-79). Essenze Derivati Agrumari, Reggio Calabria, v. 49, n. 2, p. 123-153, 1979.

ELAHI, M.; KHAN, N., The free amino acids of fresh juices of Pakistani Citrus. J. Agr. Food Chem., Washington, v. 19, n. 2, p. 260-262, 1971.

FARFAN, J. A. Os aminoácidos. In:_— Química de proteínas, aplicada à ciência e tecnologia de alimentos. 2.ed. Campinas: UNICAMP, 1994a. 134p, p. 17-30.
FARFAN, J.A. Determinação de aminoácidos livres em alimentos. In: SEMINÁRIO SOBRE ANÁLISE DE AMINOÁCIDOS EM ALIMENTOS E OUTROS MATERIAIS BIOLÓGICOS, Campinas, SP, 1994. Palestras ... Campinas: ITAL, 1994b. 60p.

GOODWIN, T.W.; MORTON, R.A. The spectrophotometric determination of tyrosine and trytophan in proteins. Biochemical Journal, Essex, v. 40, p. 628, 1946.

HAENDLER. L.; DUVERNEUIL, G. Note sur les possibilités de transformation des fruits et des "faux fruits" de l'anacardier (Anacardium occidentale). Fruits, Paris, v.25, n.5, p.379-384, 1970.

KUNEMAN, D.; BRADDOCK, J.K.; Mc CHESNEY, L.L. HPLC Profile of amino acids in fruit juices as their (1-fluoro-2,4dinitrophenyl)-5-L-alanine amide derivatives. Journal of Agricultural and Food Chemistry, Washington, v.36, p.6-9. 1988.

OOGHE, W.; DE WAELE, A. Amino acids for detection of blending and adulteration of fruit juices. Voedingsmiddelentechnologie, Zeist, v.15, n.4, p.28-33 and n.9, p.64-68, 1982a.

OOGHE, W.; DE WAELE, A. Detection of dilution and adulteration of fruit juices through amino acids standard values. Fluessiges Obst, Schoenborn v.49, n.11, p.618-628, 1982 b.

PRICE, R.L.; HOLANDA, L.F.F.; MOURA FÉ, J.A; MAIA, G. A.; MARTINS, C.B. Constituents of Brazilian Cashew apple juice. Ciência Agronômica, Fortaleza, v.5. n.1-2, p.61-65, dez. 1975.

SPACKMAN, D.H.; STEIN, W.H.; MOORE, E.S. Automatic recording apparatus for use in the chromatografy of amino acids. Analytical Chemistry, Washington, v.30, p.1190-1198, 1958.

TADEO, J. L.; ORTIZ, J. M.; MARTIM, B.; ESTELLÉS, A. Changes in nitrogen content and amino acid composition of Navel oranges during ripening. Journal Sci. Food Agric. , v. 43, p. 201 209, 1988.

VANDERCOOK, C. E.; PRICE, R. L. The application of amino acid composition to the characterization of citrus juice. Journal of Food Science, Chicago, v. 37, n. 3, p. 384-386, 1972.

VENTURA, M.M.; LIMA, I.H. Free amino acids of cashew apples (Anacardium occidentale, L.). Phyton, Vicente Lopez, v.12, n.1, p.31-34, 1959.

WALLRAUCH, S. Natural amino acid content of orange juice and effect of harvesting date. Fluessiges Obst, Schoenborn, v.47, n.2, p.47-52, 57, 1980 .

WALLRAUCH, S.; FAETHE, W. Amino acids: Criteria for the evaluation of fruit juices. In: NAGY, S.; ATTAWAY, S.A.; RHODES, M.E. (Eds). Adulteration of fruit juice and beverages. New York: Marcel Dekker, 1988. p21-48. 